\title{
Gait kinematic alterations in subjects with adult spinal deformity and their radiological determinants
}

\author{
Georges Kawkabani ${ }^{a}$, Ren 'ee Maria Saliby ${ }^{a}$, Mario Mekhael ${ }^{a}$, Rami Rachkidi ${ }^{a}$, Abir Massaad ${ }^{\text {a }}$, Ismat \\ Ghanem $^{\mathrm{a}}$, Khalil Kharrat ${ }^{\mathrm{a}}$, Gaby Kreichati ${ }^{\mathrm{a}}$, Eddy Saad ${ }^{\mathrm{a}}$, Virginie Lafage ${ }^{\mathrm{b}}$, \\ Renaud Lafage $^{\mathrm{b}}$, Wafa Skalli ${ }^{\mathrm{c}}$, Ayman Assi ${ }^{\mathrm{a}, \mathrm{c}, *}$
}

a Faculty of Medicine, University of Saint-Joseph in Beirut, Lebanon
${ }^{\mathrm{b}}$ Spine Service, Hospital for Special Surgery, New York, USA
${ }^{\mathrm{c}}$ Institut de Biomécanique Humaine Georges Charpak, Arts et Métiers ParisTech, Paris, France

\author{
Keywords: \\ Adult spinal deformity \\ 3D gait analysis \\ Sagittal alignment \\ Walking
}

\section{A B S T R A C T}

Background: Adults with spinal deformity (ASD) are known to have postural malalignment affecting their quality of life. Classical evaluation and follow-up are usually based on full-body static radiographs and health related quality of life questionnaires. Despite being an essential daily life activity, formal gait assessment lacks in clinical practice.

Research Question: What are the main alterations in gait kinematics of ASD and their radiological determinants? Methods: 52 ASD and 63 control subjects underwent full-body 3D gait analysis with calculation of joint kinematics and full-body biplanar X-rays with calculation of 3D postural parameters. Kinematics and postural parameters were compared between groups. Determinants of gait alterations among postural radiographic parameters were explored.

Results: ASD had increased sagittal vertical axis (SVA:34 $\pm 59 \mathrm{vs}-5 \pm 20 \mathrm{~mm}$ ), pelvic tilt (PT:19 $\pm 13 \mathrm{vs} 11 \pm 6^{\circ}$ ) and frontal Cobb $\left(25 \pm 21\right.$ vs $4 \pm 6^{\circ}$ ) compared to controls (all $\left.\mathrm{p}<0.001\right)$. ASD displayed decrease walking speed $(0.9 \pm 0.3$ vs $1.2 \pm 0.2 \mathrm{~m} / \mathrm{s})$, step length $(0.58 \pm 0.11$ vs $0.64 \pm 0.07 \mathrm{~m})$ and increased single support $(0.45 \pm 0.05$ vs $0.42 \pm 0.04 \mathrm{~s})$. ASD walked with decreased hip extension in stance $\left(-3 \pm 10\right.$ vs $\left.-7 \pm 8^{\circ}\right)$, increased knee flexion at initial contact and in stance ( $10 \pm 11$ vs $5 \pm 10^{\circ}$ and $19 \pm 7$ vs $16 \pm 8^{\circ}$ respectively), and decreased knee flexion/extension ROM ( $55 \pm 9$ vs $\left.59 \pm 7^{\circ}\right)$. ASD had increased trunk flexion $(12 \pm 12$ vs $\left.11^{\circ}\right)$ and reduced dynamic lumbar lordosis $\left(-11+6 \underline{12}\right.$ vs $-15 \pm 7^{\circ}$, all $\left.\mathrm{p}<0.001\right)$. Sagittal knee ROM, walking speed and step length were negatively determined by SVA; lack of lumbar lordosis during gait was negatively determined by radiological lumbar lordosis.

Significance: Static compensations in ASD persist during gait, where they exhibit a flexed attitude at the trunk, hips and knees, reduced hip and knee mobility and loss of dynamic lordosis. ASD walked at a slower pace with increased single and double support times that might contribute to their gait stability. These dynamic discrep-

ancies were strongly related to static sagittal malalignment.

\section{Introduction}

Life expectancy has increased with advancements in the medical field and healthcare. With the aging of the population, multiple pathologies have increased in numbers [1]. Most of these diseases are degenerative, occurring with the wear and tear of the tissues of the body and leading to musculoskeletal disorders, especially in the spine [2].

Adult Spinal Deformity (ASD) consists of various postural and spino- pelvic alterations of the lumbar or thoracolumbar spine, affecting one or more of the three planes [3,4]. It is defined as the presence of pain or discomfort with an increase in one of the following radiological parameters: Pelvic Tilt (PT), Sagittal Vertical Axis (SVA), Cobb angle and Thoracic Kyphosis (TK) [5]. Repercussions of ASD impact the patient physically (altered daily functions) and mentally (anxiety and depression in severe cases) [6,7]. Severity of the deformity is judged radiologically [8-10].

\footnotetext{
* Corresponding author at: Laboratory of Biomechanics and Medical Imaging, Faculty of Medicine, University of Saint-Joseph, Damascus Street, Beirut, Lebanon. E-mail address: ayman.assi@usj.edu.lb (A. Assi).
} 

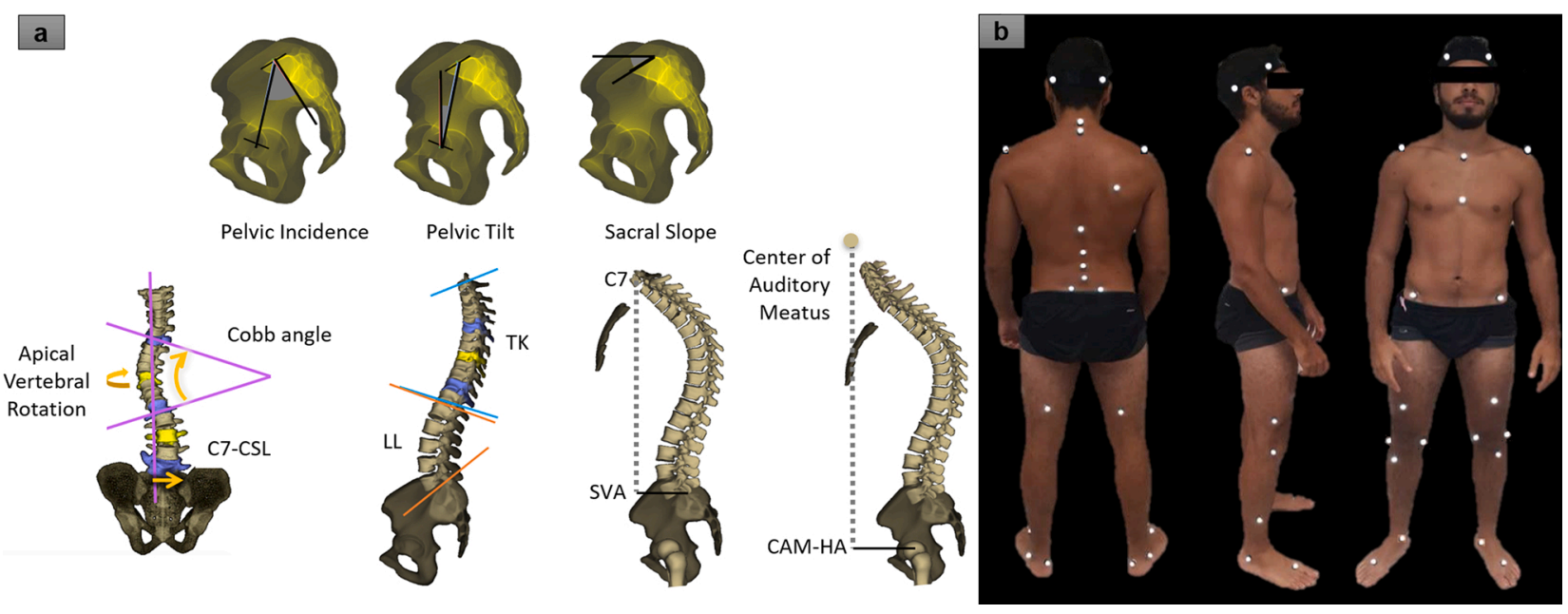

Fig. 1. a) Spino-pelvic and postural parameters: Pelvic Incidence (PI), Pelvic Tilt (PT), Sacral Slope (SS), Cobb angle, C7-CSL, Apival Vertebral Rotation (AVR), Thoracic Kyphosis (T1T12), Lumbar Lordosis (L1S1), Sagittal Vertical Axis (SVA), Center of Auditory Meatus to Hip Axis sagittal plumbline (CAM-HA); b) Placements of the reflective markers for gait acquisitions.

In a standing position, the body keeps the center of gravity over the feet while maintaining a horizontal gaze [11]. This positioning has led to the concept of the sagittal alignment, an interplay between various mechanical factors. Therefore, any spine abnormality may cause a deviation of the body's center of gravity. In such cases, multiple mechanisms to counterbalance the modifications take place [12]. In clinical routine, postural assessment is highly appreciated to better understand these mechanisms, using full body frontal and sagittal X-rays in standing position.

Compensatory mechanisms can have severe consequences on the patient, causing increased back pain, muscle fatigue, accelerated joints degeneration, and most importantly, a limitation of numerous daily life activities such as walking. Clinicians rely mostly on health-related quality of life (HRQoL) and disability questionnaires for the assessment of deformity repercussions on functionality. These questionnaires focus on the degree of capability of achieving some daily life activities, such as walking [6]. But this technique lacks objectivity and quantification.

Gait analysis is used in the research of movement analysis in the clinical field for certain pathologies (e.g., cerebral palsy, Parkinson's disease) [13-15]. However, in the setting of ASD, gait analysis is rarely used, limiting the functional evaluation and possibly the adequate management and treatment of the disease. The few available studies have mostly shown that ASD patients have altered spatial-temporal parameters in their gait $[16,17]$. Most of these studies focused on the general aspect of gait. An in-depth look at altered joint kinematics of patients with ASD would give healthcare providers additional information to improve treatments and plans of care.

Therefore, the aim of this study was to investigate the 3D kinematic alterations in subjects with ASD during gait in an attempt to evaluate objectively patient's functional limitation and to identify the underlying static radiographic determinants of these gait alterations. We hypothesized that: 1) subjects with ASD walk with alterations in their joint kinematics; 2) kinematic alterations in ASD are related to spinopelvic radiographic deformities.

\section{Material and methods}

\subsection{Study design}

This is a retrospective study on ASD patients and asymptomatic adults data collected prospectively. Enrolled ASD subjects were referred to our center by their physicians based on analysis of radiographs on which they presented any of the following radiological criteria: PT > $25^{\circ}$, SVA $>50 \mathrm{~mm}$, Cobb angle $>20^{\circ}$, and/or TK $>60^{\circ}$. All ASD patients were older than 20 years and complained from pain/discomfort. Patients with gait altering disorders not explained by their spine condition, or with recent lower limbs or spinal surgeries dating less than two years were excluded. Controls, recruited from our institution through the mailing list, were older than 20 years with no pain, no lower limbs or spinal surgery, no musculoskeletal system disorders, and no history of degenerative joint disease. This study was approved by the Ethics Committee of our institution (CEHDF1259). All participants signed an informed consent prior to the trials.

\subsection{Data acquisition}

\subsubsection{Demographics and spinopelvic parameters}

Age, sex, height and weight were collected for each subject.

Subjects underwent low dose full body biplanar X-rays (EOS ${ }^{\circledR}$, EOS Imaging, Paris, France) in free standing position [18]. Three-dimensional reconstructions of the spine and pelvis were performed using Stereos ${ }^{\circledR}$ (v1.8.99.20R) with extraction of the following radiographic parameters (Fig. 1a):

- SVA (mm) as the distance from the sagittal plumbline from the center of the $\mathrm{C7}$ vertebra to the posterior edge of the upper sacral endplate surface $(\mathrm{mm})$

- CAM-HA (mm) as the center of auditory meatus sagittal plumbline to the sacrum

- pelvic incidence PI $\left(^{\circ}\right)$

- pelvic tilt PT $\left(^{\circ}\right)$

- L1S1 lumbar lordosis LL $\left(^{\circ}\right)$

- PI-LL mismatch

- T1T12 thoracic kyphosis TK $\left(^{\circ}\right)$

- knee flexion $\mathrm{KF}\left({ }^{\circ}\right)$

- frontal Cobb angle $\left(^{\circ}\right)$

- C7-CSL (mm) as the frontal plumbline of C7 relatively to the sacrum

- Apical Vertebral Rotation AVR $\left(^{\circ}\right)$

\subsection{HRQoL and disability questionnaires}

All participants filled the following HRQoL and disability questionnaires [6,7]:

- Visual Analog Scale (VAS) varies from 0 to 10 and increases with pain severity 

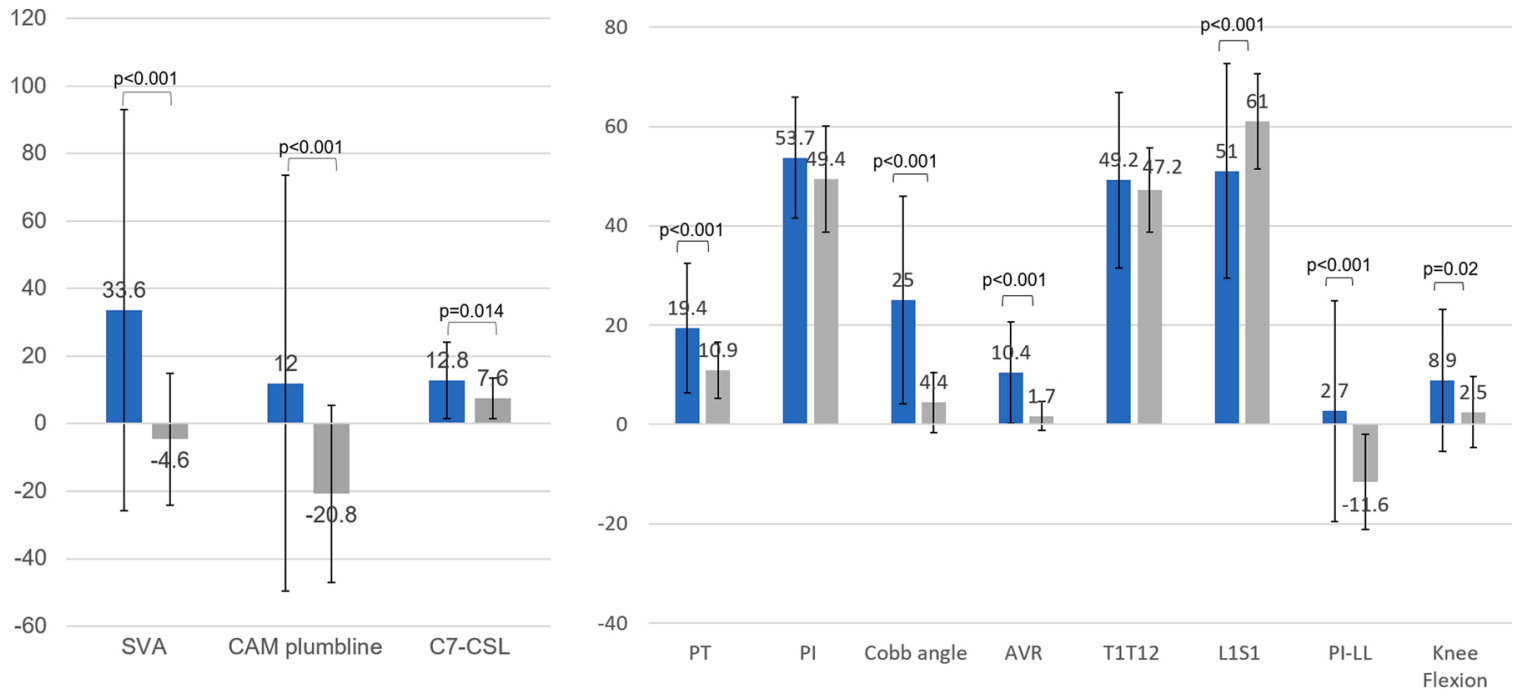

- ASD $n$ Controls

Fig. 2. Comparison of spino-pelvic and global postural parameters between ASD and controls (mean and standard deviation).

- Oswestry Disability Index (ODI) varies from 0 to 100 and increases with severity

- Short Form Health Survey (SF-36): measuring both Physical Component (PCS), and Mental Component (MCS) Summary (scores were normalized to the local population) varies from 0 to 100 and decreases with severity

- Beck's Depression Inventory (BDI) varies from 0 to 63 and increases with severity.

\subsection{Gait analysis}

Eight cameras (Vero 2.2, Vicon Motion Systems ${ }^{\circledR}$, Oxford, UK) were used to capture full-body kinematics during gait (frequency: $200 \mathrm{~Hz}$ ). The conventional Davis protocol was used for the lower limb marker set [19]. For the trunk and spine, markers were placed according to the Leardini protocol [20] on the following anatomical landmarks: right and left acromions, deepest point of the suprasternal notch, xiphoid process, and spinous processes of C7, T2, T10, L1, L3, and L5 vertebras (Fig.1b). Patients walked at self-selected speed on a 10-meter walkway. The following joint angles were calculated in the 3 planes using Nexus and ProCalc (Vicon ${ }^{\circledR}$, Oxford, UK) and normalized to the gait cycle: segmental spine motion (L3L5 relative to L1L3, L1L3 relative to T10L1, T10L1 relative to T2T10 and T2T10 relative to T2C7), trunk (pelvis relative to thorax), pelvis (pelvis relative to global reference), hip (femur relative to pelvis), knee (tibia relative to femur), ankle (foot relative to tibia), foot (foot relative to global reference). The following spatial-temporal parameters were collected: walking speed $(\mathrm{m} / \mathrm{s})$, cadence (steps/min), time of foot off (transition from stance to swing phase, in \% of gait cycle), single and double support times (s), as well as step length (m).

The gait deviation index (GDI) was also calculated [21], measuring the deviation of a specific subject's gait from a normative database, based on the pelvis and lower limb kinematics. It is scored between 0 and 100 and decreases with alteration.

\subsection{Statistical analysis}

First, a comparison of demographics between ASD and controls was performed using either Student's t-test or Mann-Whitney depending on the normality of the data (Shapiro-Wilk test). Sex was compared using Chi-squared test. HRQoL outcomes, spino-pelvic alignment and global postural parameters were compared between groups using either
Student's $t$-test or Mann-Whitney test.

Kinematic parameters (mean, minimum, maximum and range of motion ROM) during gait cycles were calculated for each joint. Kinematic and spatial-temporal parameters were compared between both groups using either Student's $t$-test or Mann-Whitney test.

The relationship between altered radiographic parameters and gait discrepancies was assessed through a univariate analysis, using linear correlations, and determinants of altered gait parameters were investigated through a multivariate analysis, using stepwise multiple linear regressions. The dependent variables were the kinematic and spatialtemporal parameters that differed between ASD and controls. The independent parameters were demographics and spino-pelvic and global postural parameters that were significant in the univariate analysis. Adjusted $\mathrm{R}^{2}, \beta$ and $\mathrm{p}$-values were reported for each model.

Statistical analyses were performed using XLSTAT (version 2019, Addinsoft, Paris, France). The level of significance was set at 0.05 and Bonferroni corrections were applied when multiple correlations were computed.

\section{Results}

\subsection{Comparison between ASD and controls}

Data was collected from 52 ASD patients $(39 \mathrm{~F}$ and $13 \mathrm{M})$ and 63 controls (32 F and $31 \mathrm{M}$ ). Sex distribution was different between groups $(\mathrm{p}=0.001)$. The two groups matched in age (ASD $=43 \pm 21$ years, vs Control $=40 \pm 12$ years, $\mathrm{p}=0.6$ ) and weight (ASD $=71 \pm 16 \mathrm{~kg}$ vs Control $=72 \pm 14 \mathrm{~kg}, \mathrm{p}=0.52$ ). ASD patients were on average $4 \mathrm{~cm}$ shorter than controls (ASD $=163 \pm 11 \mathrm{~cm}$ vs Control $=167 \pm 9 \mathrm{~cm}$, $\mathrm{p}=0.017$ ). The BMI did not vary between groups (ASD $=26.9 \pm 6.2 \mathrm{Kg}$ / $\mathrm{m}^{2}$ vs Controls $=25.7 \pm 3.9 \mathrm{Kg} / \mathrm{m}^{2}, \mathrm{p}=0.48$ ).

Out of the 52 ASD patients, 37 had scoliosis, 15 had hyperkyphosis, and the rest being enrolled based on their sagittal malalignment (SVA $>5 \mathrm{~cm}$ and/or $\mathrm{PT}>25^{\circ}$ ).

ASD patients scored significantly lower on the PCS than controls (44.5 vs. 51.6, $\mathrm{p}<0.001$ ). ASD suffered from moderate pain in general (VAS:4.4 vs. 2.3, p < 0.001), showed significantly increased disability (ODI:25.7 vs. 10, $\mathrm{p}<0.001$ ) and expressed higher depression levels than controls (BDI:8.7 vs. $4.7, \mathrm{p}=0.005$ ).

Sagitally, ASD subjects had increased SVA compared to controls (33.6 $\pm 59.3 \mathrm{~mm}$ vs. $-4.6 \pm 19.6 \mathrm{~mm}, \mathrm{p}<0.001$, Fig. 2). This forward trunk and head shift was also seen with the CAM-HA values 
Table 1

Gait parameters and comparison between ASD and controls.

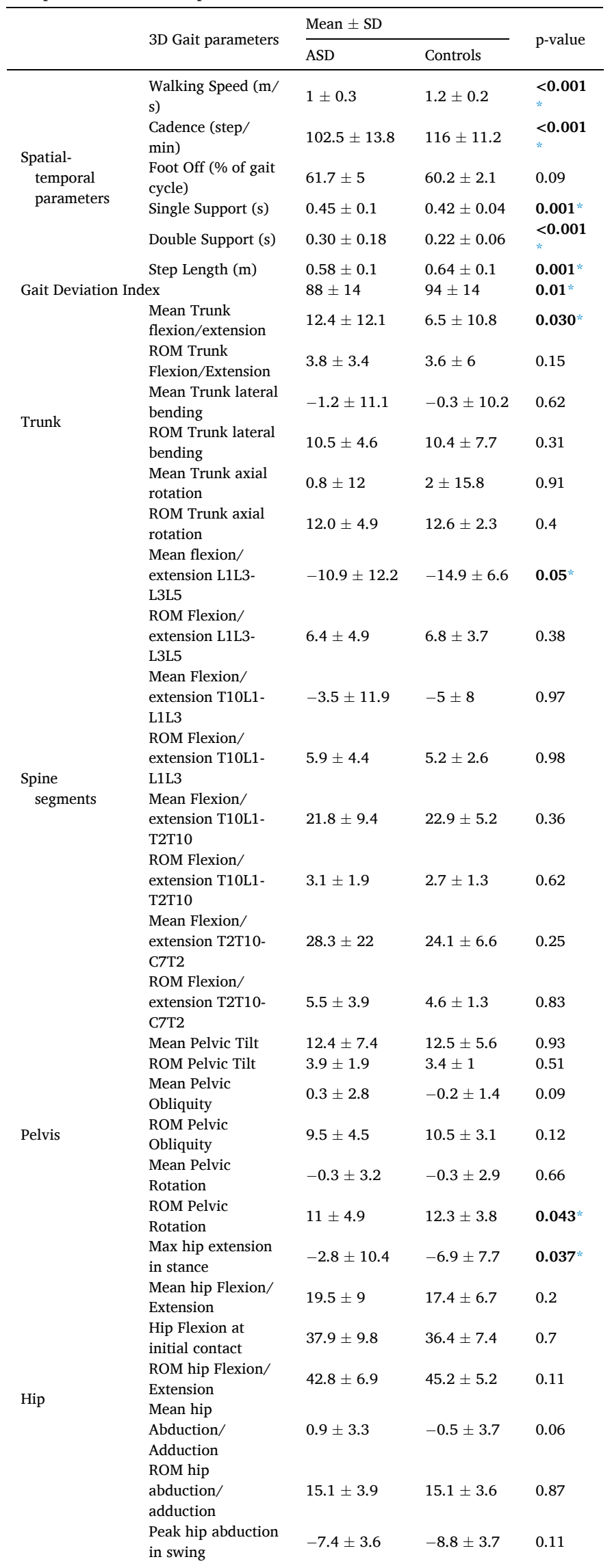

Table 1 (continued)

\begin{tabular}{|c|c|c|c|c|}
\hline & \multirow{2}{*}{ 3D Gait parameters } & \multicolumn{2}{|l|}{ Mean \pm SD } & \multirow{2}{*}{ p-value } \\
\hline & & ASD & Controls & \\
\hline \multirow{8}{*}{ Knee } & $\begin{array}{l}\text { ROM hip Internal/ } \\
\text { External Rotation }\end{array}$ & $42.8 \pm 20.3$ & $40.2 \pm 14.7$ & 0.81 \\
\hline & $\begin{array}{l}\text { Mean hip Internal/ } \\
\text { External Rotation } \\
\text { in stance }\end{array}$ & $-5 \pm 19.2$ & $-1.1 \pm 14$ & 0.50 \\
\hline & $\begin{array}{l}\text { Knee flexion at } \\
\text { initial contact }\end{array}$ & $10.1 \pm 10.6$ & $4.8 \pm 9.7$ & $0.003^{*}$ \\
\hline & $\begin{array}{l}\text { Max knee Flexion } \\
\text { in stance }\end{array}$ & $19.3 \pm 7.1$ & $15.8 \pm 7.6$ & $0.027^{*}$ \\
\hline & $\begin{array}{l}\text { Max knee extension } \\
\text { in stance }\end{array}$ & $6 \pm 6.8$ & $2.3 \pm 6.5$ & 0.006 \\
\hline & $\begin{array}{l}\text { Max knee flexion in } \\
\text { swing }\end{array}$ & $58.8 \pm 8.5$ & $59.1 \pm 9.4$ & 0.4 \\
\hline & $\begin{array}{l}\text { ROM knee Flexion/ } \\
\text { Extension }\end{array}$ & $55.3 \pm 8.5$ & $59.2 \pm 6.9$ & $0.021^{*}$ \\
\hline & $\begin{array}{l}\text { Mean Knee } \\
\text { Flexion/Extension }\end{array}$ & $21.7 \pm 6$ & $19.7 \pm 6.4$ & 0.2 \\
\hline
\end{tabular}

* Bold: significant p-value.

(ASD: $12 \pm 61.6 \mathrm{~mm}$ vs controls: $-20.8 \pm 26.2 \mathrm{~mm}, \mathrm{p}<0.001$ ). PT was significantly increased in ASD $\left(19.4 \pm 13.1^{\circ}\right.$ vs $10.9 \pm 5.7^{\circ}, \mathrm{p}<0.001$, Fig. 2). ASD patients had a significantly lower lumbar lordosis L1S1 $\left(51 \pm 21.6^{\circ}\right.$ vs. $\left.61 \pm 9.6^{\circ}, \mathrm{p}=0.035\right)$ and a higher knee flexion $\left(7.3 \pm 14.0^{\circ}\right.$ vs. $\left.1.1 \pm 5.9^{\circ}, \mathrm{p}=0.02\right)$ and presented with a larger frontal Cobb (25 $\pm 20.9^{\circ}$ vs $4.4 \pm 6.1^{\circ}$, p $<0.001$, Fig. 2$)$.

ASD patients displayed slower walking speed, lower cadence, longer single and double support times and shorter step length compared to controls $(0.9 \pm 0.3 \mathrm{~m} / \mathrm{s}$ vs. $1.2 \pm 0.2 \mathrm{~m} / \mathrm{s}, 102.5 \pm 13.8 \mathrm{steps} / \mathrm{min}$ vs $116 \pm 11.2 \mathrm{steps} / \mathrm{min}, 0.45 \pm 0.05$ vs. $0.42 \pm 0.04 \mathrm{~s}, 0.30 \pm 0.18$ vs. $0.22 \pm 0.06 \mathrm{~s}, 0.58 \pm 0.11$ vs. $0.64 \pm 0.07 \mathrm{~m}$ respectively; all $\mathrm{p} \leq 0.001$; Table 1).

GDI was significantly lower in ASD compared to controls ( $88 \pm 14$ vs. $94 \pm 14, \mathrm{p}=0.01$ ). Pelvic kinematics did not differ between ASD and controls. However, ASD patients had a reduced maximal hip extension during stance phase $\left(-3 \pm 10^{\circ}\right.$ vs $\left.-7 \pm 8^{\circ}, \mathrm{p}=0.037\right)$, an increased knee flexion at initial contact $\left(10 \pm 11^{\circ}\right.$ vs $\left.5 \pm 10^{\circ}, \mathrm{p}=0.003\right)$ and in stance phase $\left(19 \pm 7^{\circ}\right.$ vs $16 \pm 8^{\circ}, \mathrm{p}=0.027$; Table 1$)$. ASD had a generally reduced knee flexion/extension ROM during the whole gait cycle $\left(55 \pm 9^{\circ}\right.$ vs $\left.59 \pm 7^{\circ}, \mathrm{p}=0.021\right)$.

In the upper body, ASD displayed increased trunk flexion $\left(12 \pm 12^{\circ}\right.$ vs $\left.6 \pm 11^{\circ}, \mathrm{p}=0.03\right)$. Their dynamic lumbar lordosis was reduced, showing a loss of lordosis during gait $\left(-11 \pm 12^{\circ}\right.$ vs $\left.-15 \pm 7^{\circ}, \mathrm{p}<0.05\right)$.

An example of altered gait kinematics and spatial-temporal parameters of an ASD patient is displayed in Fig. 3.

\subsection{Radiological determinants of gait alterations in ASD}

The univariate analysis showed several significant correlations between the altered radiographic parameters and gait discrepancies (Fig. $4 \mathrm{a}$ and b). The highest correlations were seen with SVA and CAMHA, both being positively correlated to the lack of hip extension in stance ( $r=0.56$ and $r=0.62$, respectively). GDI was negatively correlated to both SVA and CAM-HA ( $r=-0.57$ and $r=-0.49$, respectively). Walking speed was negatively correlated to SVA and knee flexion $(\mathrm{r}=-0.70$ and $\mathrm{r}=-0.62$, respectively, Fig. $4 \mathrm{~b})$.

The multivariate analysis showed that the lack of maximum hip extension in stance was determined by CAM-HA ( $\beta=0.62$, adjusted$\left.\mathrm{R}^{2}=0.37\right)$. The reduced knee extension at initial contact was determined by the radiological PT and the radiological L1S1 $(\beta=0.38$ and $\beta=-0.29$, respectively, adjusted $-R^{2}=0.35$ ). The sagittal knee ROM was determined by SVA $\left(\beta=-0.56\right.$, adjusted- $\left.\mathrm{R}^{2}=0.30\right)$. The lack of dynamic lumbar lordosis L1L3-L3L5 during gait was determined by radiological L1S1 ( $\beta=-0.58$, adjusted- $\mathrm{R}^{2}=0.33$ ). Walking speed and step length were 


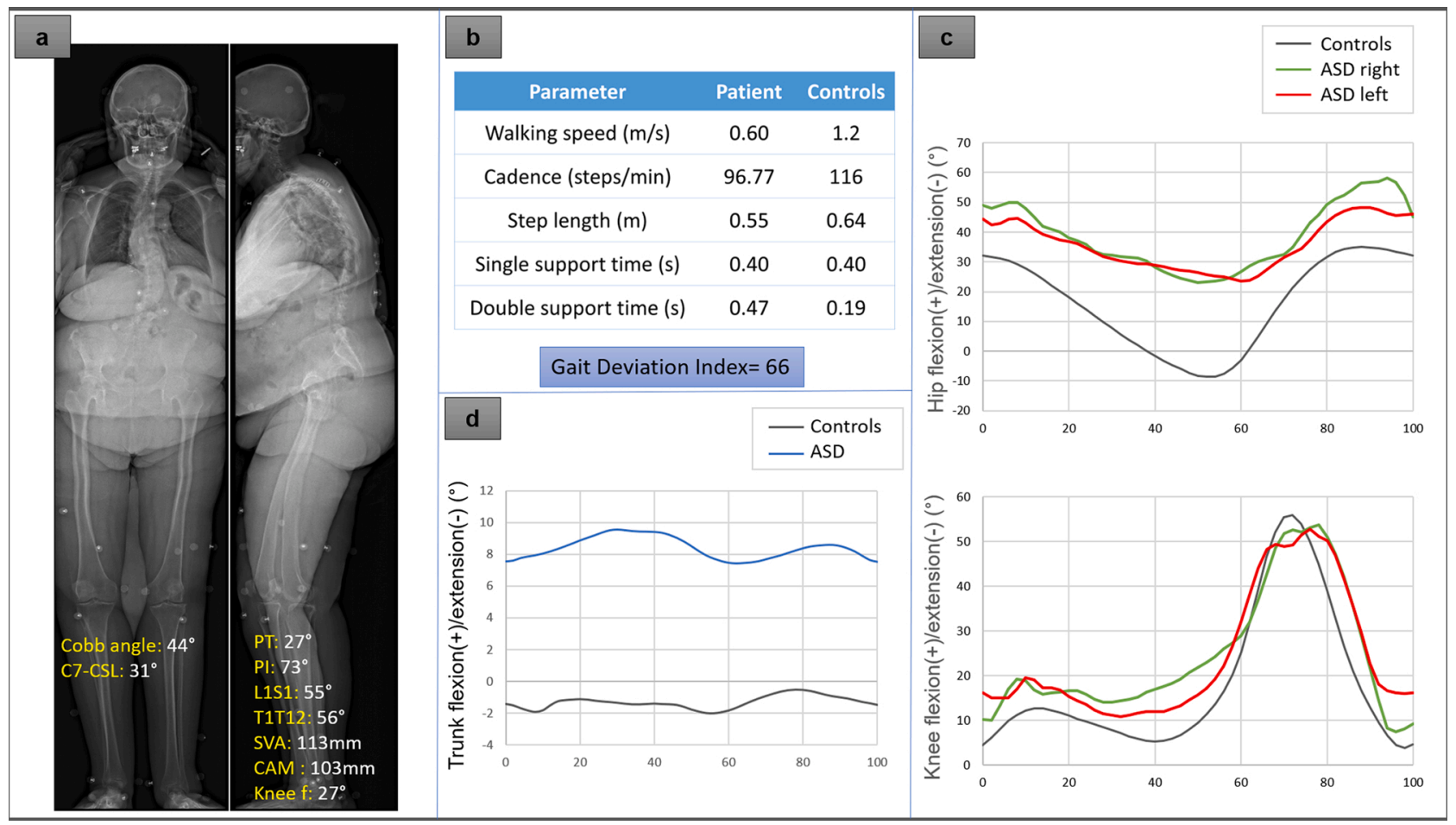

Fig. 3. Example of an ASD patient: a) radiological parameter, b) spatial-temporal parameters, c) hip and knee flexion-extension during gait, d) trunk flexionextension during gait.
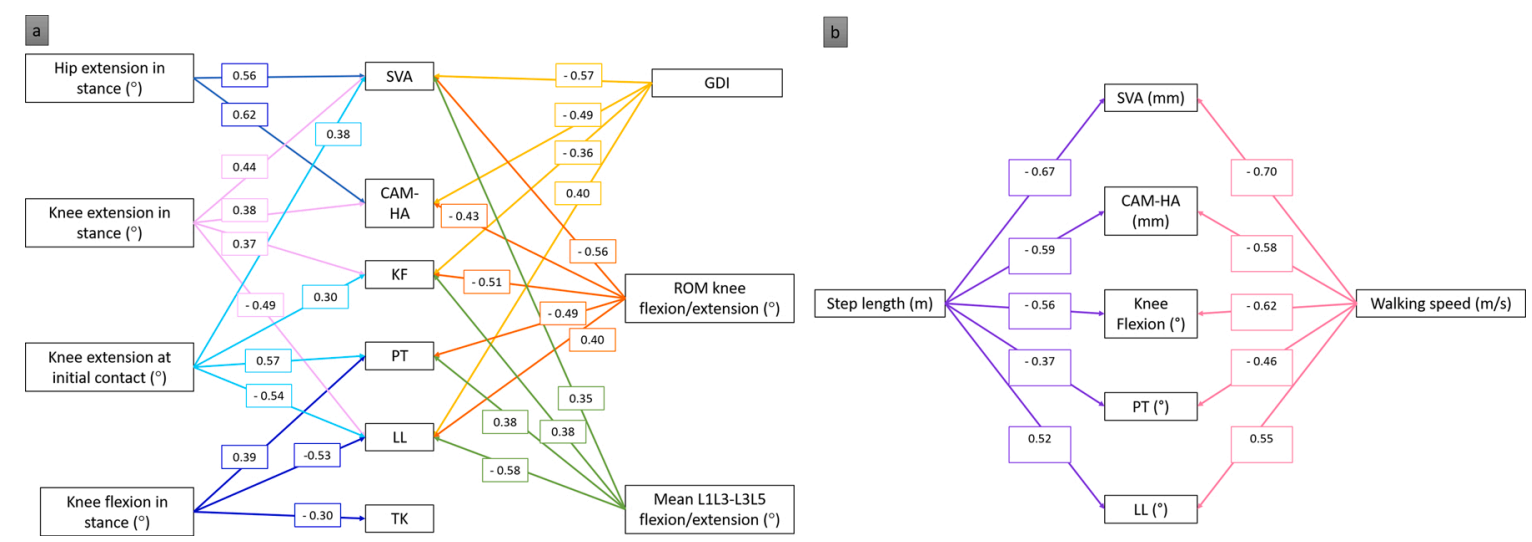

Fig. 4. a) Correlations (Pearson's r) of gait kinematics with spino-pelvic and global postural parameters. b) Correlations (Pearson's r) of spatial-temporal with spinopelvic and global postural parameters.

both determined by SVA $\left(\beta=-0.58\right.$, adjusted- $\mathrm{R}^{2}=0.30 ; \beta=-0.55$, adjusted- $\mathrm{R}^{2}=0.52$, respecively). The GDI was determined by SVA $\left(\beta=-0.57\right.$, adjusted- $\left.R^{2}=0.32\right)$. Some of these relationships were displayed in Fig. 5.

\section{Discussion}

Spinal deformity negatively affects patients' quality of life. A quantifiable evaluation technique of patient's functionality still lacks in clinical practice. Therefore, motion analysis could fill this gap to analyze daily life tasks such as gait in patients with spinal deformities. Previous studies have shown that ASD patients with sagittal malalignment tend to retrovert their pelvis, extend their hips, bend their knees and tilt their pelvis backward, to reposition their center of mass over their feet on standing radiographs [22]. However, these mechanisms are not fully explored in dynamic situations such as gait and evidence in the literature is scarce with minimal exploration of joints kinematics. This study evaluated gait analysis of the spine, pelvis and lower limbs in the three planes in order to better assess the functionality of patients with ASD.

The radiological analysis showed that the ASD population of this study suffer from sagittal malalignment, with moderate to severe alteration in sagittal parameters such as SVA, PT and PI-LL, similarly to the literature $[23,24]$. On free standing radiographs, a decreased lumbar lordosis was noticed in the ASD group, resulting in a forward shift of the trunk (increased CAM-HA and SVA). As mentioned earlier, compensation for the sagittal malalignment starts with the pelvis. The ASD population of this sample had greater pelvic retroversion, in order to reposition their center of gravity. Some patients had to recruit their knees (increased radiographic knee flexion) as an additional compensatory mechanism. Moreover, the ASD patients in this study suffered both on the physical level (lower PCS and greater ODI) and mental level (higher BDI) as previously observed $[7,25,26]$.

On the functional level, gait analysis showed that ASD patients walked at slower pace, with shorter steps and longer support time, as 

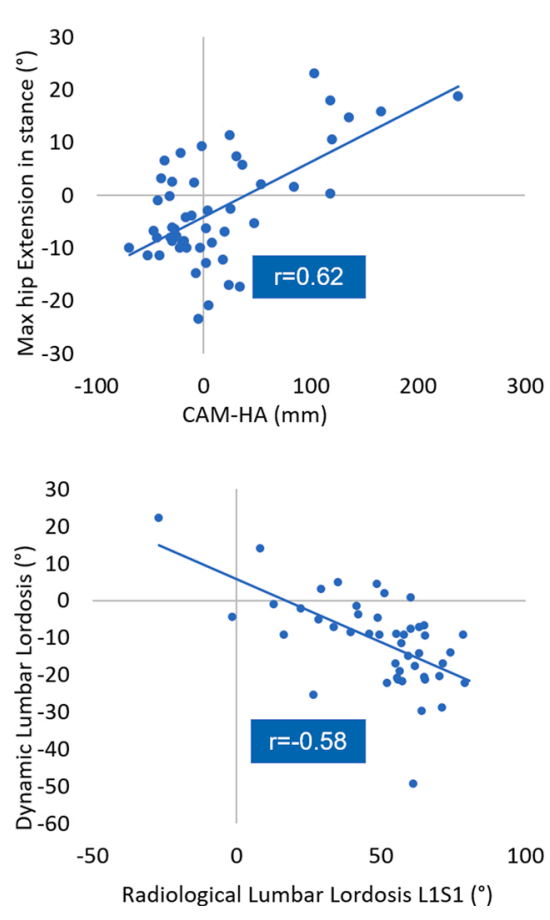
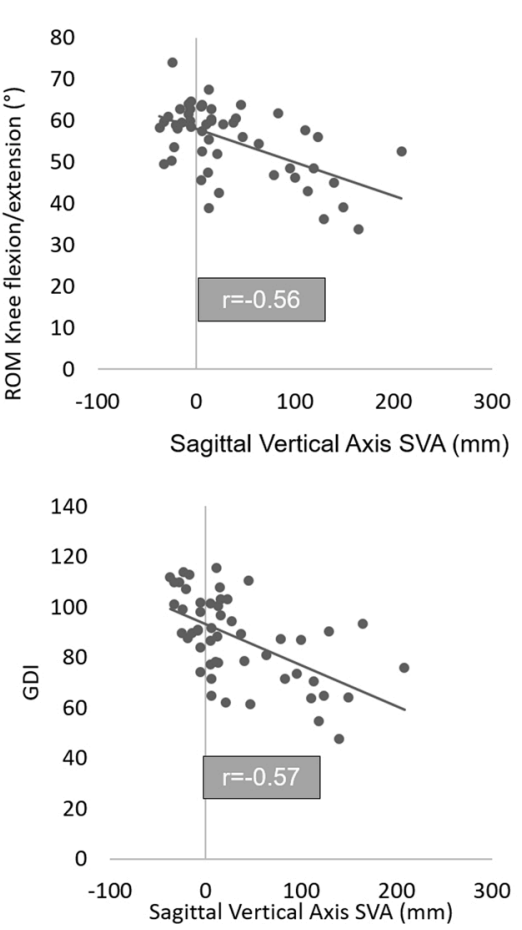
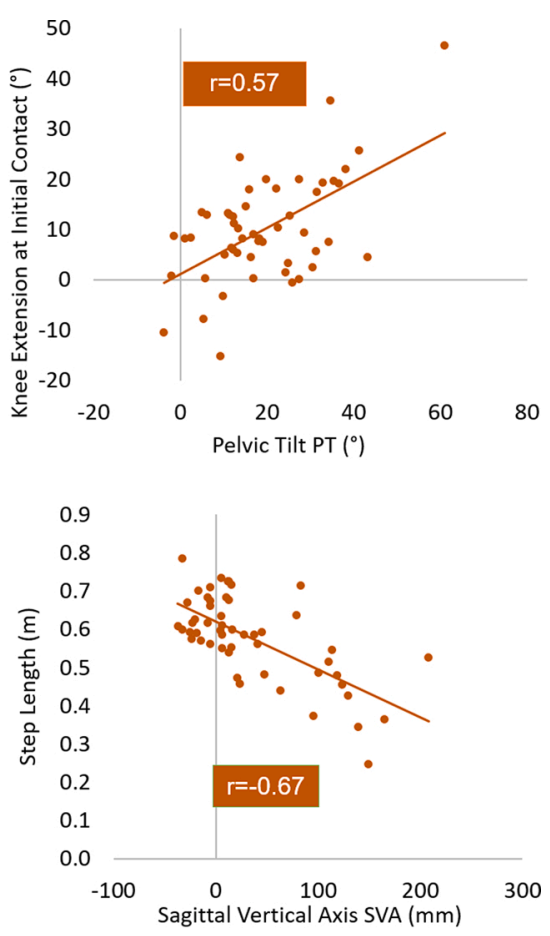

Fig. 5. Correlations (Pearson's r) of gait kinemtics and spatial-temporal parameters with their main radiological determinants.

previously described in the literature, to maintain better stability during walking $[16,17]$. Joints and segment kinematics revealed that most of the changes occurred in the sagittal plane, evoking the sagittal spino-pelvic alignment. ASD patients' attitude during gait is similar to their static positioning, with the compensatory mechanisms seen on static radiographs present during walking: a flexed attitude at the hip and the knee, along with the forward bending of the trunk. The increased hip flexion (lack of extension), during the transition from stance to swing phase, is probably generated by the forward truncal inclination. Knee flexion was also increased, corroborating the persistence of the chain of compensation during walking. This knee flexion was present during the whole cycle, with a globally decreased range of motion. A possible explanation is that knee flexion would allow for better stability and movement control and easier repositioning of the center of gravity above the feet (Fig. 3). These gait discrepancies of ASD patients in this study, were related to the skeletal radiological abnormalities, as shown in the chain of correlations, deduced from the univariate and multivariate analysis.

In the standing position, the decreased lumbar lordosis has caused both increased pelvis retroversion pelvis and forward shift of the trunk. These static deformities were correlated to the gait alterations in ASD. The forward shift of the trunk was the main determinant of the lack of hip extension during the transition from stance to swing phase. This lack of hip extension is unavoidable to maintain stability, since the trunk is shifted forward at this specific moment of the gait cycle. In other words, a greater hip extension would project forward the center of the gravity even further, causing the subject to fall.

ASD subjects walked with a greater knee flexion, mainly determined by their lack of lordosis and pelvic retroversion seen on radiographs. Additionally, their knees had a reduced mobility during walking, mainly determined by their forward shift of the trunk. Similarly to the lack of hip extension, a reduced knee extension while walking helps maintain enough stability to compensate the forward shift of the trunk, and shift backwards their center of gravity.

The lack of lordosis seen on radiographs persisted during walking and was the main determinant of the lack of dynamic lordosis during gait. Additionally, the alteration of GDI, walking speed and step length were mainly correlated to the increased forward shift of the trunk. These correlations might suggest that a possible correction of the aforementioned radiological alterations could correct the gait abnormalities in ASD patients.

This study had some limitations. Even though ASD and control populations were not matched for sex and height, gait comparisons yielded to the same results when controlling for these two confounding factors. Moreover, the ASD population was not homogeneous; a large number of old adolescents with idiopathic scoliosis, with only frontal imbalance, was included. However, even with a heterogenous ASD population, gait discrepancies were found when compared to controls.

This study evaluated joint kinematic limitations in ASD during walking in relationship to their static radiographical alterations. Future studies should analyze gait stability in ASD by evaluating the synergy between the center of mass and center of pressure in the frontal and sagittal planes while walking [27].

In conclusion, ASD patients walk at a slower pace with smaller steps and longer support time. The compensation chain seen on static radiographs was present during gait, with the forward shift of the trunk being compensated mostly by hip and knee flexions. These dynamic discrepancies were determined by several altered radiographic parameters. Future studies should evaluate if surgical correction or physical therapy could reverse these mechanisms in order to achieve a better gait and therefore, a better quality of life.

\section{Declaration of Competing Interest}

The authors report no declarations of interest.

\section{Acknowledgment}

This research was funded by the University of Saint-Joseph (grant FM361) and EUROSPINE (TFR2020\#22). The funding sources did not intervene in study design; in the collection, analysis and interpretation of data; in the writing of the report; and in the decision to submit the article for publication. 


\section{References}

[1] P.D. United Nations, Department of Economic and Social Affairs, World Population Ageing 2017 - Highlights (ST/ESA/SER.A/397), 2017. http://www.un.org/en/ development/desa/population/publications/pdf/ageing/WPA2017_Highlights. pdf.

[2] M.G. Fehlings, L. Tetreault, A. Nater, T. Choma, J. Harrop, T. Mroz, C. Santaguida, J.S. Smith, The aging of the global population: the changing epidemiology of disease and spinal disorders, Neurosurgery 77 (2015) S1-S5, https://doi.org/ 10.1227/NEU.0000000000000953.

[3] J.S. Smith, C.I. Shaffrey, S. Bess, M.F. Shamji, D. Brodke, L.G. Lenke, M.G. Fehlings, V. Lafage, F. Schwab, A.R. Vaccaro, C.P. Ames, Recent and emerging advances in spinal deformity, Clin. Neurosurg. (2017), https://doi.org/10.1093/neuros/ nyw048.

[4] F. Schwab, A. Dubey, L. Gamez, A.B. El Fegoun, K. Hwang, M. Pagala, J.P. Farcy, Adult scoliosis: prevalence, SF-36, and nutritional parameters in an elderly volunteer population, Spine (Phila. Pa. 1976) 30 (2005) 1082-1085, https://doi. org/10.1097/01.brs.0000160842.43482.cd.

[5] H.J. Kim, S. Iyer, L.P. Zebala, M.P. Kelly, D. Sciubba, T.S. Protopsaltis, M. Gupta, B. J. Neuman, G.M. Mundis, C.P. Ames, J.S. Smith, R. Hart, D. Burton, E.O. Klineberg, Perioperative neurologic complications in adult spinal deformity surgery, Spine (Phila. Pa. 1976). 42 (2017) 420-427, https://doi.org/10.1097/ BRS.0000000000001774.

[6] F. Schwab, A. Dubey, M. Pagala, L. Gamez, J.P. Farcy, Adult scoliosis: a health assessment analysis by SF-36, Spine (Phila. Pa. 1976) 28 (2003) 602-606, https:// doi.org/10.1097/01.BRS.0000049924.94414.BB.

[7] S. Bess, B. Line, K.-M. Fu, I. McCarthy, V. Lafage, F. Schwab, C. Shaffrey, C. Ames, B. Akbarnia, H. Jo, M. Kelly, D. Burton, R. Hart, E. Klineberg, K. Kebaish, R. Hostin, G. Mundis, P. Mummaneni, J.S. Smith, International spine study group, the health impact of symptomatic adult spinal deformity: comparison of deformity types to United States population norms and chronic diseases, Spine (Phila. Pa. 1976) 41 (2016) 224-233, https://doi.org/10.1097/BRS.0000000000001202.

[8] F.J. Schwab, B. Blondel, S. Bess, R. Hostin, C.I. Shaffrey, J.S. Smith, O. BoachieAdjei, D.C. Burton, B.A. Akbarnia, G.M. Mundis, C.P. Ames, K. Kebaish, R.A. Hart, J.-P. Farcy, V. Lafage, International spine study group (ISSG), radiographical spinopelvic parameters and disability in the setting of adult spinal deformity, Spine (Phila. Pa. 1976) 38 (2013) E803-E812, https://doi.org/10.1097/ BRS.0b013e318292b7b9.

[9] B.G. Diebo, J.J. Varghese, R. Lafage, F.J. Schwab, V. Lafage, Sagittal alignment of the spine: What do you need to know? Clin. Neurol. Neurosurg. 139 (2015) 295-301, https://doi.org/10.1016/J.CLINEURO.2015.10.024.

[10] S.D. Glassman, Md,K.M. Bridwell, J.R. Dimar, W.M. Horton, S.M. Berven, F. Schwab, The impact of positive sagittal balance in adult spinal deformity, Spine (Phila. Pa. 1976) 30 (2005) 2024-2029, https://doi.org/10.1097/01. brs.0000179086.30449.96.

[11] J. Dubousset, Three-dimensional analysis of the scoliotic deformity, Pediatr. Spine. 1994 (1994) 479-496. http://scholar.google.com/scholar?hl=en\&btnG=Search $\& q=$ intitle:Three-Dimensional + Analysis + of + the + Scoliotic + Deformity\# 0 .

[12] V. Lafage, F. Schwab, W. Skalli, N. Hawkinson, P.-M. Gagey, S. Ondra, J.-P. Farcy, Standing balance and sagittal plane spinal deformity: analysis of spinopelvic and gravity line parameters, Spine (Phila. Pa. 1976). 33 (2008) 1572-1578, https:// doi.org/10.1097/BRS.0b013e31817886a2.

[13] M. Pau, F. Corona, R. Pili, C. Casula, F. Sors, T. Agostini, G. Cossu, M. Guicciardi, M. Murgia, Effects of physical rehabilitation integrated with rhythmic auditory stimulation on spatio-temporal and kinematic parameters of gait in parkinson's disease, Front. Neurol. 7 (2016) 126, https://doi.org/10.3389/fneur.2016.00126.

[14] J.R. Davids, Quantitative gait analysis in the treatment of children with cerebral palsy, J. Pediatr. Orthop. 26 (2006) 557-559, https://doi.org/10.1097/01. bpo.0000226284.46943.a3.

[15] S.A. Sangeux M, Kinematic deviation in children with cerebral palsy. Orthop. Manag. Child. With Cereb. Palsy, 2015.

[16] R. Haddas, K.L. Ju, T. Belanger, I.H. Lieberman, The use of gait analysis in the assessment of patients afflicted with spinal disorders, Eur. Spine J. (2018), https:// doi.org/10.1007/s00586-018-5569-1.

[17] M. Yagi, H. Ohne, T. Konomi, K. Fujiyoshi, S. Kaneko, M. Takemitsu, M. Machida, Y. Yato, T. Asazuma, Walking balance and compensatory gait mechanisms in surgically treated patients with adult spinal deformity, Spine J. 17 (2017) 409-417, https://doi.org/10.1016/j.spinee.2016.10.014.

[18] Y. Chaibi, T. Cresson, B. Aubert, J. Hausselle, P. Neyret, O. Hauger, et al., Fast 3D reconstruction of the lower limb using a parametric model and statistical inferences and clinical measurements calculation from biplanar X-rays, Comput. Methods Biomech. Biomed. Engin. 15 (2012) 457-466, https://doi.org/10.1080 10255842.2010 .540758

[19] R.B. Davis, S. Õunpuu, D. Tyburski, J.R. Gage, A gait analysis data collection and reduction technique, Hum. Mov. Sci. 10 (1991) 575-587, https://doi.org/ 10.1016/0167-9457(91)90046-Z

[20] A. Leardini, F. Biagi, A. Merlo, C. Belvedere, M.G. Benedetti, Multi-segment trunk kinematics during locomotion and elementary exercises, Clin. Biomech. Bristol Avon (Bristol, Avon) 26 (2011) 562-571, https://doi.org/10.1016/J. CLINBIOMECH. 2011.01.015.

[21] M.H. Schwartz, A. Rozumalski, The gait deviation index: a new comprehensive index of gait pathology, Gait Posture 28 (2008) 351-357, https://doi.org/ 10.1016/j.gaitpost.2008.05.001.

[22] R. Lafage, F. Schwab, V. Challier, J.K. Henry, J. Gum, J. Smith, R. Hostin, C. Shaffrey, H.J. Kim, C. Ames, J. Scheer, E. Klineberg, S. Bess, D. Burton, $\mathrm{V}$. Lafage, International spine study group, defining spino-pelvic alignment thresholds, Spine (Phila. Pa. 1976) 41 (2016) 62-68, https://doi.org/10.1097/ BRS.0000000000001171.

[23] M. Yagi, S. Kaneko, Y. Yato, T. Asazuma, Standing balance and compensatory mechanisms in patients with adult spinal deformity, Spine (Phila. Pa. 1976) 42 (2017) E584-E591, https://doi.org/10.1097/BRS.0000000000001901.

[24] R. Lafage, B. Liabaud, B.G. Diebo, J.H. Oren, S. Vira, S. Pesenti, T.S. Protopsaltis, T. J. Errico, F.J. Schwab, V. Lafage, Defining the role of the lower limbs in compensating for sagittal malalignment, Spine (Phila. Pa. 1976). (2017), https:// doi.org/10.1097/BRS.0000000000002157.

[25] F. Pellisé, A. Vila-Casademunt, M. Ferrer, M. Domingo-Sàbat, J. Bagó, F.J.S. PérezGrueso, A. Alanay, A.F. Mannion, E. Acaroglu, Impact on health related quality of life of adult spinal deformity (ASD) compared with other chronic conditions, Eur. Spine J. 24 (2014) 3-11, https://doi.org/10.1007/s00586-014-3542-1.

[26] B.G. Diebo, D. Cherkalin, C.M. Jalai, N.V. Shah, G.W. Poorman, G.A. Beyer, F. A. Segreto, V. Lafage, Q. Naziri, J.M. Newman, W.P. Urban, T.J. Errico, F. J. Schwab, C.B. Paulino, P.G. Passias, Comparing psychological burden of orthopaedic diseases against medical conditions: investigation on hospital course of hip, knee, and spine surgery patients, J. Orthop. 15 (2018) 297-301, https://doi. org /10.1016/j.jor.2018.02.010.

[27] M. Mekhael, C. Labaki, A.J. Bizdikian, Z. Bakouny, J. Otayek, F. Yared, A. Massaad, W. Skalli, I. Ghanem, A. Assi, How do skeletal and postural parameters contribute to maintain balance during walking? Hum. Mov. Sci. 72 (2020) https://doi.org/ 10.1016/j.humov.2020.102658. 